\title{
CARACTERIZAÇÃO E ESTUDO DAS ETAPAS DE PRODUÇÃO E VIDA DE PRATELEIRA DE KOMBUCHÁS
}

\author{
Vitória Ribaldo Ribeiro*, Ana Valéria Ulhano Braga, Kazumi Kawasaki Ramos, Flávio Luís Schmidt.
}

\begin{abstract}
Resumo
O Kombuchá vem se tornando uma bebida popular em diversos países devido ao seu potencial probiótico, atrelado à preocupação atual da sociedade com a qualidade nutricional dos alimentos. No entanto, no Brasil, o Kombuchá ainda é considerado um produto novo, produzido por pequenos produtores ou de forma caseira. Esse trabalho propõe a caracterização e o estudo de 3 kombuchás dos sabores: melissa com capim limão, abacaxi e gengibre; aroeira com maçã verde e menta; e hibisco com frutas vermelhas, em diferentes etapas de produção e fermentação. A caracterização foi realizada através das análises de acidez, $\mathrm{pH}$, sólidos solúveis, compostos fenólicos totais, análises microbiológicas tradicionais e por metagenoma, além de uma análise sensorial para avaliar a aceitação do consumidor.
\end{abstract}

Palavras-chave: Kombuchá, físico química, fermentação

\section{Introdução}

No Brasil, ainda são escassos os estudos a respeito das variáveis na produção do Kombuchá, sendo, desta forma, fundamental o estudo e a análise da composição química do produto que varia ao longo da fermentação, além do tipo de microrganismo presente $e$ as características do substrato escolhido (tipo de chá), sua concentração e a quantidade de açúcar presente (HRNJEZ et al., 2014).

Este projeto de pesquisa baseia-se no estudo das etapas de produção e vida de prateleira de kombuchás nos sabores melissa, hibisco e aroeira, coletados durante a primeira e segunda fermentações.

\section{Resultados e Discussão}

A Tabela 1 e 2 mostram respectivamente os resultados das análises físico-químicas e microbiológicas dos kombuchás.

Tabela 1. $\mathrm{pH}$, Acidez, Brix e compostos fenólicos totais no início e final da fermentação dos Kombuchás

\begin{tabular}{|c|c|c|c|c|c|}
\hline \multicolumn{2}{|c|}{ Amostra } & $\mathrm{pH}$ & $\begin{array}{c}\text { Acidez (vol. } \\
\mathrm{NaOH} \\
0,1 \mathrm{~N} / 100 \mathrm{ml} \\
\text { amostra) }\end{array}$ & $\begin{array}{l}\text { Sólidos } \\
\text { solúveis } \\
\text { ('Brix) }\end{array}$ & $\begin{array}{l}\text { Compostos } \\
\text { fenólicos } \\
\text { (mg ác. } \\
\text { gálico/L) }\end{array}$ \\
\hline \multirow{2}{*}{ Melissa } & & & & & \\
\hline & Fir & & & & \\
\hline \multirow{2}{*}{ Hibisco } & Inicial & & & & \\
\hline & Final & 2,8 & & & \\
\hline \multirow[b]{2}{*}{ Aroeira } & Inicial & $4,1 \pm 0,0$ & & & $45,5 \pm 0,7$ \\
\hline & Final & $3,6 \pm 0,0$ & $21,0 \pm 1,7$ & $1,3 \pm 0,1$ & $63,2 \pm 0,9$ \\
\hline
\end{tabular}

Tabela 2. Resultado das análises microbiológicas (UFC/ml) e metagenoma dos Kombuchás

\begin{tabular}{|c|c|c|}
\hline & Bactérias & Fungos \\
\hline \multirow[b]{2}{*}{ Melissa } & $7,5 \times 10^{5} \mathrm{UFC} / \mathrm{ml}$ & $2,48 \times 10^{5} \mathrm{UFC} / \mathrm{ml}$ \\
\hline & Bacillus pumilus & $\begin{array}{l}\text { Saccharomyces cerevisiae } \\
\text { Pichia kudriavzevii } \\
\text { Lachancea fermentati }\end{array}$ \\
\hline \multirow[b]{2}{*}{ Aroeira } & $3,14 \times 10^{8} \mathrm{UFC} / \mathrm{ml}$ & $9,18 \times 10^{6} \mathrm{UFC} / \mathrm{ml}$ \\
\hline & $\begin{array}{l}\text { Bacillus subtilis } \\
\text { Bacillus carboniphilus } \\
\text { Bacillus megaterium }\end{array}$ & $\begin{array}{l}\text { Pichia kudriavzevii } \\
\text { Lachancea fermentati }\end{array}$ \\
\hline \multirow[b]{2}{*}{ Hibisco } & $1,08 \times 10^{6} \mathrm{UFC} / \mathrm{ml}$ & $6,50 \times 10^{5} \mathrm{UFC} / \mathrm{ml}$ \\
\hline & Bacillys humi & $\begin{array}{l}\text { Pichia kudriavzevii } \\
\text { Brettanomyces bruxelensis }\end{array}$ \\
\hline
\end{tabular}

A análise sensorial foi realizada com consumidores préselecionados através da aceitação das 3 amostras produzidas no laboratório, além de 2 outras amostras comerciais com características sensoriais diferentes: sabores morango com hibisco; e hibisco com cranberry (Figura 1).

Figura 1. Resultado do teste de aceitação dos kombuchás

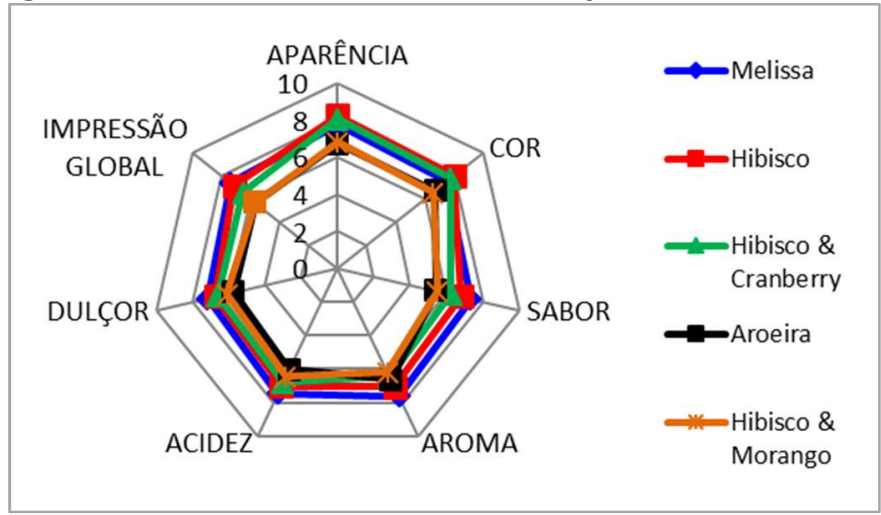

Conclusões

- Como esperado, foi possível perceber queda de pH e sólidos solúveis durante a fermentação de kombuchá, além do aumento da acidez e aumento dos compostos fenólicos.

- A alta contagem de microrganismos é esperada por ser uma bebida fermentada e que não passa por tratamento térmico, e os microrganismos identificados não são patógenos.

- Os kombuchás de melissa, hibisco e hibisco com cranberry apresentaram maior aceitação do que os demais produtos.

- O trabalho despertou interesse para futuros estudos, tendo em vista que inúmeras variáveis podem influenciar na característica da bebida, assim como na aceitação do consumidor conforme análise sensorial.

\section{Agradecimentos}

A empresa de kombuchá KOM, de Atibaia - SP, pela coleta e doação de kombuchás. Laboratório de Frutas e Hortaliças pela infraestrutura para a realização da pesquisa.

HRNJEZ, D.; VASTAG, Z.; MILANOVIC, S.; VUKIC, V.; ILIC`IC', M.;

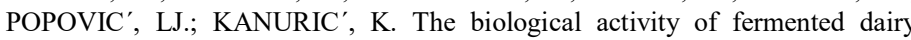
products obtained by kombucha and conventional starter cultures during storage. Journal of Functional Foods, v. 10, p. 271-279, 2014. 